\title{
Laser-based scanning to manage geotechnical risk in deep mines
}

\author{
DB Counter Glencore Canada Corporation, Kidd Creek Operations, Canada
}

\begin{abstract}
Kidd Creek mines has been either adopting new technology as it becomes available or adapting existing techniques to aid in assessing risk associated with ground and support systems failure, particularly risk associated with high-magnitude seismic events or significant deformation associated with mining at extreme depths. Over the past four years, the mine has used laser-based scanners as an aid in determining where and by how much the rock mass has deformed, both as a direct result of seismic events and as a function of rock mass deformation associated with mining. The scanning data is being used to qualify, if not quantify, how much strain has been introduced into the ground support systems, and it is being used as part of the rehabilitation and proactive re-support process to ensure that ground support systems have sufficient yield capacity remaining to withstand the largest possible future seismic event, in an effort to lower risk to personnel and mine production. Some recent data are presented along with a preliminary assessment of what the scanner information is capable of providing, and suggestions for future research are provided.
\end{abstract}

Keywords: laser scan, rockburst, support capacity, risk

\section{Introduction}

One of the largest dilemmas in geotechnical engineering is determining the residual capacity available in ground support tendons and surface membranes following large-scale deformation or rockbursts associated with mining. It is impossible to adequately instrument every area of the mine to monitor actual deformation, not only regarding cost and logistics but also regarding data analysis and database maintenance. With the advent of new wireless technology, remote data acquisition from dispersed geotechnical displacement or load instruments may be easier to achieve; however, ensuring that the instruments are located in the exact area of the underground workings subjected to the damage caused by some future seismic event or mining process, and that the instruments are oriented to measure the deformation that actually occurs, makes this an unrealistic ideal.

Much effort has recently gone into the development of instrumented ground support tendons that will eventually be capable of broadcasting load or strain status over an 'internet of things' network. This technology is still in its infancy in terms of the production and installation of ubiquitous 'smart' tendons, and to be useful, a significant percentage of all ground support tendons would need to be instrumented in order to provide meaningful data over the scale of mining-related major seismic events where damage can occur on multiple levels, affecting hundreds of meters of lateral development. The incremental cost premium over non-instrumented tendons would need to be very low if they are to be adopted by industry, and the necessary means of remotely acquiring the data needs to be developed, as it would be ideal if the status of the support systems could be queried, without the need to enter the area affected following a large event or large production blast in order to download data. Current work by the National Research Council and others is geared towards either passive sensors, which require a 'wand' to be passed in close proximity to the sensor to obtain the data, or towards local wired systems, where wires are subject to damage by blasting, mine equipment or bursting. Specialist suppliers offer services to instrument small numbers of bolts provided by the mine operator, but the costs are generally high, and the reliability of the sensors has occasionally been problematic, with the point of attachment between the strain gauge and external readout cables (which are connected to data loggers) subject to damage upon installation or from 
interaction with mining equipment. Large networks of instrument cables are considered unsupportable from a maintenance standpoint, thus wireless connections are the preferred means to obtain this data, and that technology has not yet been integrated with current low-cost instrumented rockbolt research (Hyett et al. 2013, 2014; Lopez-Pacheco 2018).

\section{Historic tendon assessment technologies}

Kidd Creek Operations has been continuously adopting new technologies as they have become available to aid in remote data acquisition and in the gathering of meaningful information that can aid in the assessment of changing ground conditions over time. This has been driven by historic, damaging seismic and structural failures over the life of the mine (Counter 2014) and the challenges of excavating large open stopes at depths approaching $3 \mathrm{~km}$, where the in situ stress levels are up to $50 \%$ higher than the rock mass strength. Large static deformation associated with lateral development advance, and regional deformation associated with bulk mining and slip along major fault systems, have resulted in significant early loading on ground support tendons, often leading to local failure, in the absence of direct dynamic loading. While physical observation of the condition of the rock mass and appearance of the visible portion of support systems has historically been used as the principal means of assessing the status of the support capacity within the industry, it is becoming critical in deep or high stress orebodies to have a viable method of assessing the general status of the support systems that can be rapidly deployed over large areas of the mine with relatively low resource requirements.

Global deformation data over large areal extents provides information that can be used to help calibrate mine stress models (local plastic strain as well as regional deformation boundaries) and define areas that are actively deforming as mining is occurring, thus enabling more proactive identification of development that should be isolated by restriction barricades following production blasting, or that is at higher risk of damage during any ensuing seismic activity because the support systems within those areas are more likely to be at higher levels of induced load or strain and hence have less residual capacity. This also allows targeted rehabilitation in advance of possible future seismicity. The biggest issue has been (and will continue to be for the future) the calibration of these systems to the point where they can be used on a regular basis to assess support capacity and geotechnical risk.

Historically, pull tests have been endorsed by many ground control practitioners as a means of assessing support capability, current loading and remaining capacity. Where friction stabilisers or standard mechanical rockbolts are used, a pull test can determine current loading (additional load required to initiate slip or elongation of the bolt), but in the case of resin-grouted tendons, pull tests are of limited benefit. The physical nature of the fully resin-encapsulated tendon limits the gauge length over which strain can occur, and any load applied to the exposed head of the bolt only measures the condition of the tendon over a limited distance beyond the point of embedment in the resin in those cases where the tendon is to be 'locked' in by ridges, ribs or other surface upsets. Where plates are already taking load due to transfer from the membrane or from rock mass deformation immediately adjacent to the head of the tendon, a pull test can indicate the residual capacity available to the point of head failure; however, it does not provide any data on the condition of the embedded length of the tendon. Similarly, pull tests are not likely to determine whether the tendon has already failed at some depth beneath the surface of the rock mass that is deeper than the minimum or critical embedment length. In highly deforming ground, any reference measurement of elongation of the bolt under load must take into account the capacity of the surface of the deformed rock mass to strain under the applied load of the jack, which is not a measure of bolt elongation so much as it is a measure of void space and compressibility of the immediately adjacent fractured rock mass. How to partition this deformation between elongation of the bolt and compression of the underlying strata is potentially difficult to determine because typically the measurement is taken between the jack body and the ram and is not externally referenced to a datum point that is not likely to be affected by the test.

Similar problems are known to exist during the 'design' and establishment of the dynamic rating of support, where most index tests to assign capacity to support tendons do not measure the system response but only 
that of the tendons being tested, and then only under extremely constrained loading situations, namely purely axial impact loading. These tests do not represent the full loading conditions experienced by the ground support system under true rockburst conditions, including shear, bulking, off-axis loading, 'locking' of the ground support elements into the rock mass due to differential displacement, et cetera (Counter 2014; Simser 2007), nor do they account for the degradation of the support capacity over time due to ongoing static deformation, corrosion, et cetera.

\section{Simultaneous localisation and mapping (SLAM) laser scanner}

Kidd Creek have been employing a hand-held laser-based mobile scanning system since the second half of 2015, initially in support of research being undertaken by Evan Jones as a part of his doctoral thesis under the guidance of David Beck of Beck Engineering in Sydney, Australia. That device, a ZEB1 scanner, was used to measure over 40 scan-km of drift during a 16-month period, with many locations being scanned multiple times. Kidd subsequently purchased a ZEB-REVO scanner in early 2017 and have regularly used it to continue scanning most of the active workings within the mine in order to provide a background dataset that can be used for comparative purposes if a future high-magnitude seismic event occurs or for determining how much static deformation has been occurring due to regional mine closure over time.

Although very much a work in progress, the goal is to calibrate the deformation history of an opening to the residual capacity left within the ground support systems. Several recent rockbursts and local failures of support systems have allowed 'end points' to be established from scanner data, indicating where the support system is known to have failed, which can be associated with a measured amount of displacement over a known areal extent. The temporal distribution of the deformation has also been observed, such that specific stopes being mined as well as specific seismic events have been linked to measured deformation.

\section{$4 \quad$ Observations}

In the following examples, the deformation over time is depicted by multiple views of the development obtained using CloudCompare, where individual scans are analysed for differential movement sequentially. Where multiple images are present, the scans have been compared to a common 'start date' so that the images show progressive cumulative displacement over time. They have then been 'calibrated' against observed failures of the ground support tendons or membrane in order to define 'tolerable' limits of deformation.

\subsection{7-S05 Stope}

During development and drilling for the 77-S05 Stope, located at the upper right side of Figure 1, multiple seismic events occurred $\left(M_{N} 1.2\right.$ on 21 August 2017 while taking a slash for the 75-S05 drill drift (DD), $M_{N} 0.6$ on 14 October 2017 while bolting in the 75-S05 XC, $M_{N} 0.5$ on 8 November 2017 while completing the reaming of the 77-S05 Stope slot raise, $M_{N} 1.0$ on 11 November 2017 during blasting the final round in the 75-S05 DD, and $M_{N} 2.02$ on 12 November 2017 approximately 29 hours later), which caused sufficient damage to require local rehabilitation. After the first production blast on 22 December 2017, the 77-S05 Stope was left full of muck to provide passive support to allow re-entry onto the top sill, given the ongoing seismic hazard and risk of caving. There were further seismic events $\left(M_{N} 1.0\right.$ on 23 January 2018 and $M_{N} 1.5$ on 24 January 2018) while remotely drilling holes for the stope final blast to ensure operators were physically removed from the potential seismogenic zone, which was isolated by barricades on multiple horizons. The final blast was accompanied by a $M_{N} 2.7$ event on 27 January 2018 while access to the area was restricted under the site seismic re-entry protocol. $A M_{N} 1.75$ event occurred on 28 January 2018 with the onset of fully autonomous mucking from the surface (to ensure the continued safety of personnel), and a $M_{N} 1.26$ occurred on 13 March 2018 near the end of mucking, which was completed on 21 March 2018. Access to the seismogenic zone at the overcut elevation was restricted by barricades throughout the entire mucking process, as per normal isolation protocols. 


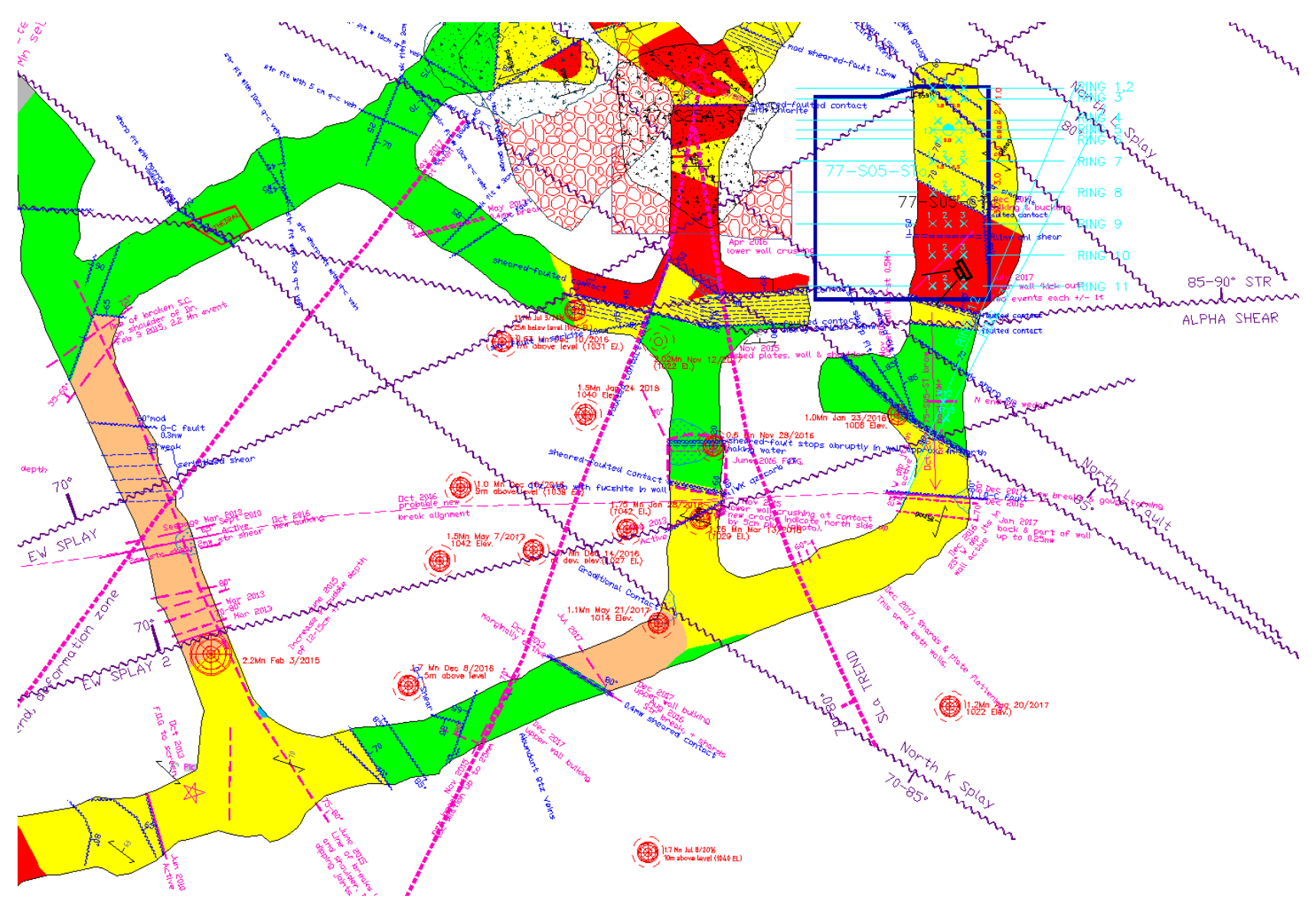

Figure 1 Geology, south abutment 7,500 level. Major faults in purple. Recent mining-induced failure trends in magenta, including shear rupture planes (heavy dashed lines). Higher magnitude seismic events within $20 \mathrm{~m}$ above or below level at red circular icons. Rhyolite (yellow), andesite diorite (green), altered quartz porphyry (peach) and massive sulphides (red). The 77-S05 Stope is at the top right at the northern end of the 75-S05 XC (dark blue outline)

The CloudCompare images in Figure 2 show the changes to the west wall of the 75-S05 XC over roughly an eight-month period from 6 June 2017 through 31 January 2018, covering the development, production drilling and blasting associated with mining the 77-S05 Stope over four discrete periods. The first covers the deformation and seismicity associated with mining the nearby 75-S26B Stope from 6 June to 18 July 2017, before the start of drill drift development for the 77-S05 Stope. The second scan covers the development and raisebore processes, from 18 July to 18 November 2017 . The third scan covers the period from 6 June 2017 to 26 January 2018, which incorporates all changes associated with development up to the time of the first production blast, and the seismic activity associated with production drilling in preparation for the final blast. The final scan shows the accumulated displacement for the period from 6 June 2017 to 31 January 2018, which covers the full development, drilling and blasting cycles of the stope, not including removal of the broken ore following the final blast or filling.

All the areas identified in yellow, red or dark blue in the CloudCompare images required re-support at various times during the extraction of the 77-S05 Stope and again after the final blast in order to regain access to the crosscut for the subsequent extraction of the 75-S05 Stope in the third quarter of 2018. Ground support failures consisted of loss of plates and failed heads from 22-mm diameter $D$ bolts and failure of 0-gauge straps in areas with more than $13 \mathrm{~cm}$ of deformation, and breaking of mesh in areas with more than $7 \mathrm{~cm}$ of deformation. Rehabilitation consisted of removal of badly fractured rock (scaling or purging) and re-support with resin-based $D$ bolts, or inflatable bolts in badly fractured ground, and the installation of additional dynamic bolts (Yield-Lok) within 0-gauge mesh straps along the walls. The back and wall of the drill drift were also cable bolted, with twin plain strand 15-mm diameter cables, which were 
plated with custom blocks and tensioned to 10 tonnes per hole ( 5 tonnes per strand) to ensure that the bearing blocks were firmly connected to the cables while providing a minimum amount of pre-tension to maximise long-term capacity.

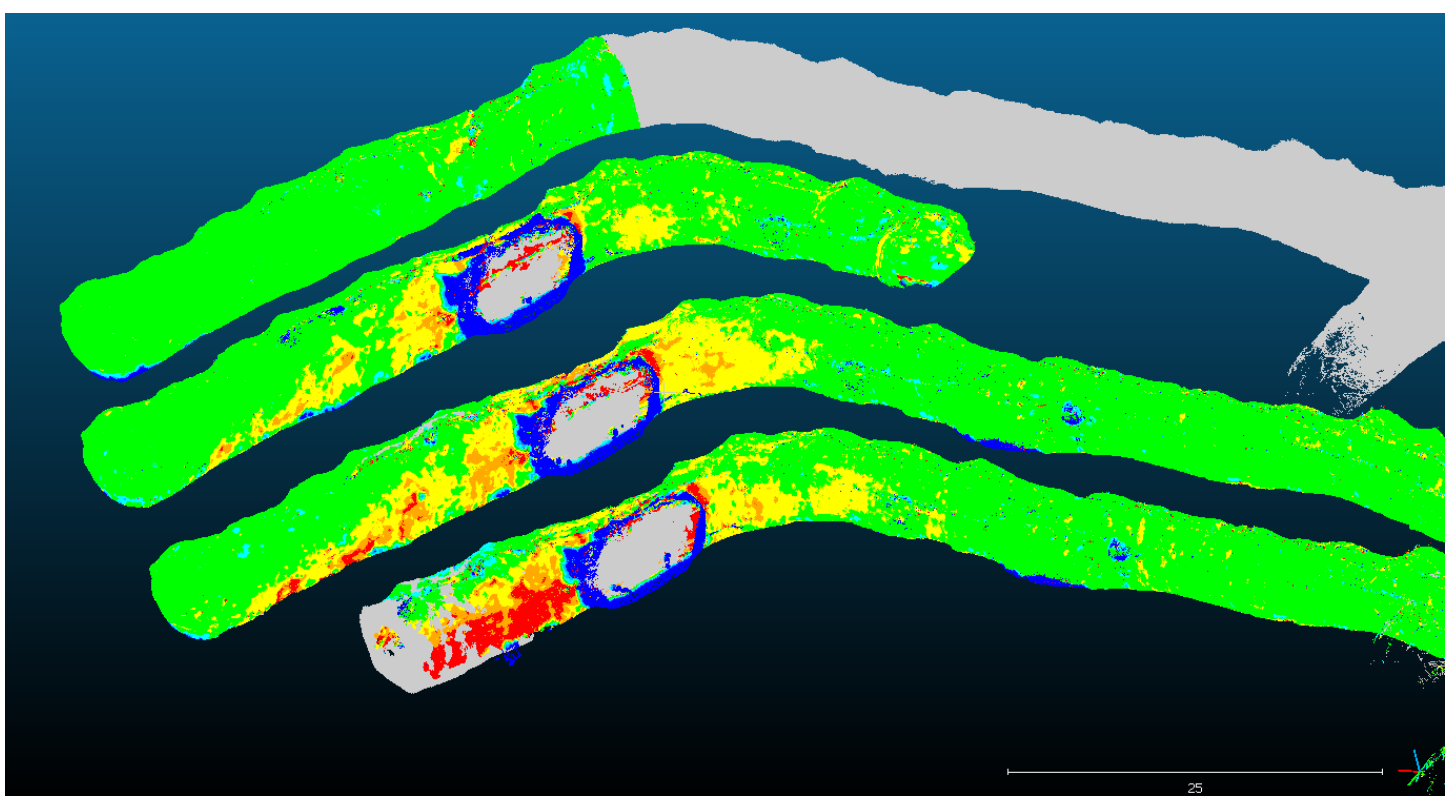

Figure 2 CloudCompare scans (top to bottom) of the periods from 6 June 2017 versus 18 July 2017seismicity associated with blasting in nearby 75-S26B Stope; from 18 July 2017 versus 14 November 2017-seismicity associated with development of 75-S05 XC and drill drift (burst damage to lower walls) and reaming of the 77-S05 Stope slot raise; from 6 June 2017 versus 26 January 2018-seismicity following first toe blast in 77-S05 Stope on 22 December 2017 and ensuing production drilling; and from 6 June 2017 versus from 31 January 2018-following 77-S05 Stope final blast including $M_{N} 2.7$ and $M_{N} 1.75$ events. Areas not covered by both scans being used in the comparison process appear grey. Rehabilitation, including scaling, can result in a reduction in deformation and hence the appearance of less cumulative deformation over time, as seen between the third and fourth scan sets above

The CloudCompare images in Figure 3 show both sides of the 75-S05 XC and 75-S05 drill drift restricted to the period from 14 November 2017 to 21 March 2018 to solely show the deformation associated with the mining and seismic activity generated by the 77-S05 Stope, which is easier to reconcile with the strain plot from the Abaqus stress model associated with the same stope shown in Figure 5 (Beck Engineering Pty Ltd 2018). Historically, the stress models did not consider the excavation of access drifts separately from the extraction of the stope. 


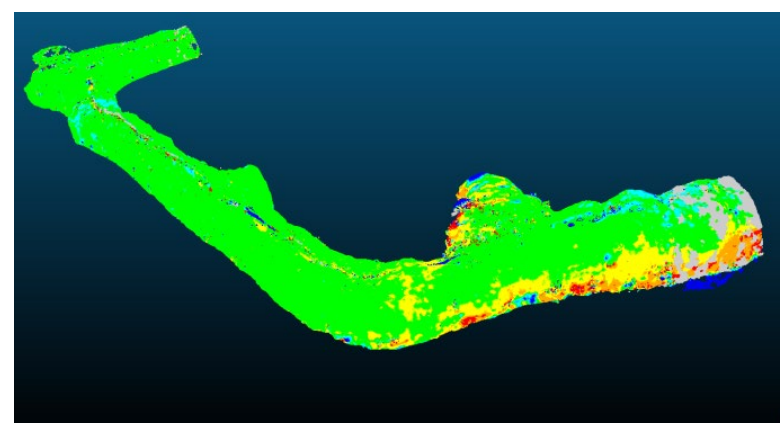

(a)

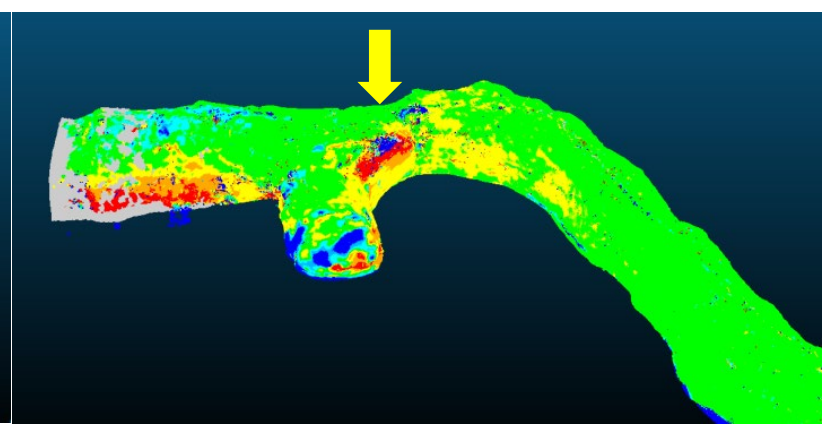

(b)

Figure 3 CloudCompare scans facing northwest (a) and southeast (b) showing the damage associated with blasting and mucking the 77-S05 Stope during the period from 14 November 2017 to 21 March 2018

Figure 4 shows an area of the west wall of the 75-S05 XC at the entrance to the 75-S05 drill drift, facing southwest, where an area of the rock mass failed but was contained by the mesh. The blue area below the arrow in Figure 3(b) with an increased distance between successive scans in excess of $13 \mathrm{~cm}$ is outlined in Figure 4 where rock has fallen from the upper shoulder along a fault trace and accumulated in the mesh in the red area with a decreased distance in excess of $13 \mathrm{~cm}$ immediately below it, as shown in Figure 3 . Where the wall has bulked along the fault trace as shown by the yellow area in Figure 3 where distances have decreased between $7 \mathrm{~cm}$ and $13 \mathrm{~cm}$ between scans, it has been outlined in a black dashed line in Figure 4. This area changed relative to the previous scan in Figure 2, as ongoing rock mass damage occurred during the mucking phase of the 77-S05 Stope caused by the removal of passive support, regional rock mass deformation and the subsequent seismicity. Note the correlation with the high-strain areas predicted in the Abaqus stress model as shown in Figure 5 (Beck Engineering Pty Ltd 2018)

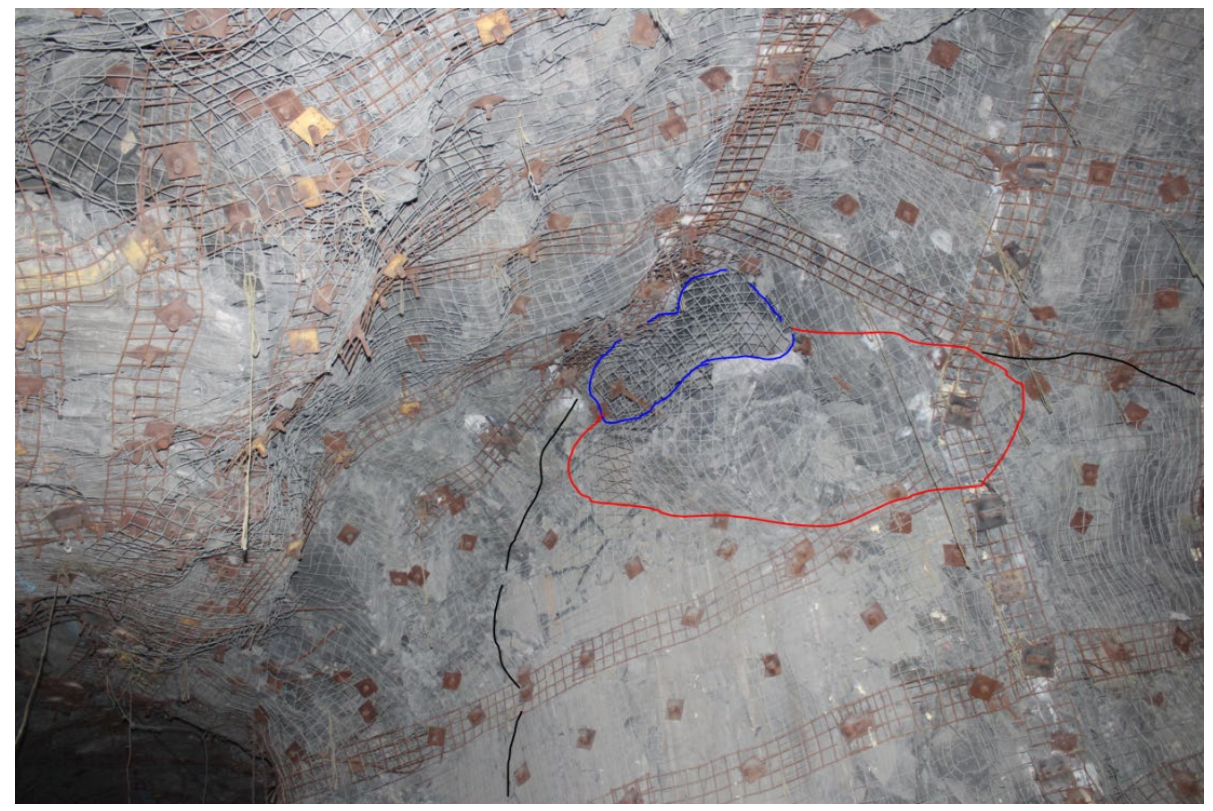

Figure 4 Southwest corner of the 75-S05 XC and 75-S05 drill drift intersections, 21 March 2018 


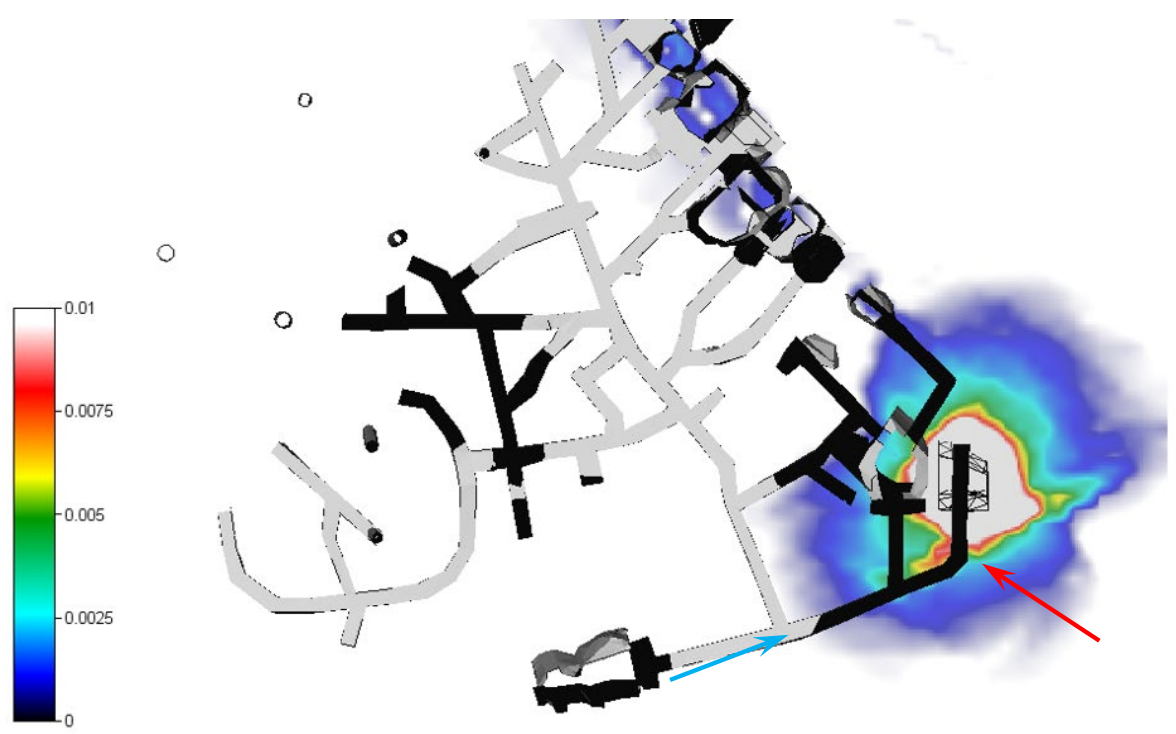

Figure 5 Abaqus stress model strain associated with 77-S05 Stope. The strain boundary caused by the North $\mathrm{K}$ fault is aligned with the red arrow, and the bulking and dilation following the East-West Shear Zone splay (as shown in Figure 1) is aligned with the blue arrow. Those areas are coincident with the most damage observed in the scan images in Figures 2 and 3 (Beck Engineering Pty Ltd 2018)

\section{$4.2 \quad 71-S 43$ Stope}

On the 7,000 level, scans have shown localised damage associated with regional fault slip along specific shear failures. A $M_{N} 1.96$ rockburst occurred approximately one minute after the final blast on 18 December 2018 in the 71-S43 Stope, located at the top of the partial level geology plan shown in Figure 6. This is the first stope to be mined above the historic 'South Lens' mining and was expected to cause significant slip and deformation in the south abutment within the area affected by the 2009 and 2011 $M_{N} 3.8$ shear rupture events (Counter 2014). The event caused moderate damage, particularly within the 70-S46 XC, in the immediate area of the Seismic Break 1A (SB1A) shear rupture surface, where it displaced $+/-400$ tonnes, even though relatively little material was actually ejected and not contained by ground support ( $<3$ tonnes). The area had been continuously deforming for over a year due to other south abutment mining (Stopes 75-S26B, 65-767, 73-848, 70-S43, 69-883, 77-S05, 74-888, 75-S05, 69-789 and 62-SL1), which have all either had an influence on deformation or triggered seismicity in the south abutment in proximity to the seismic break systems. 


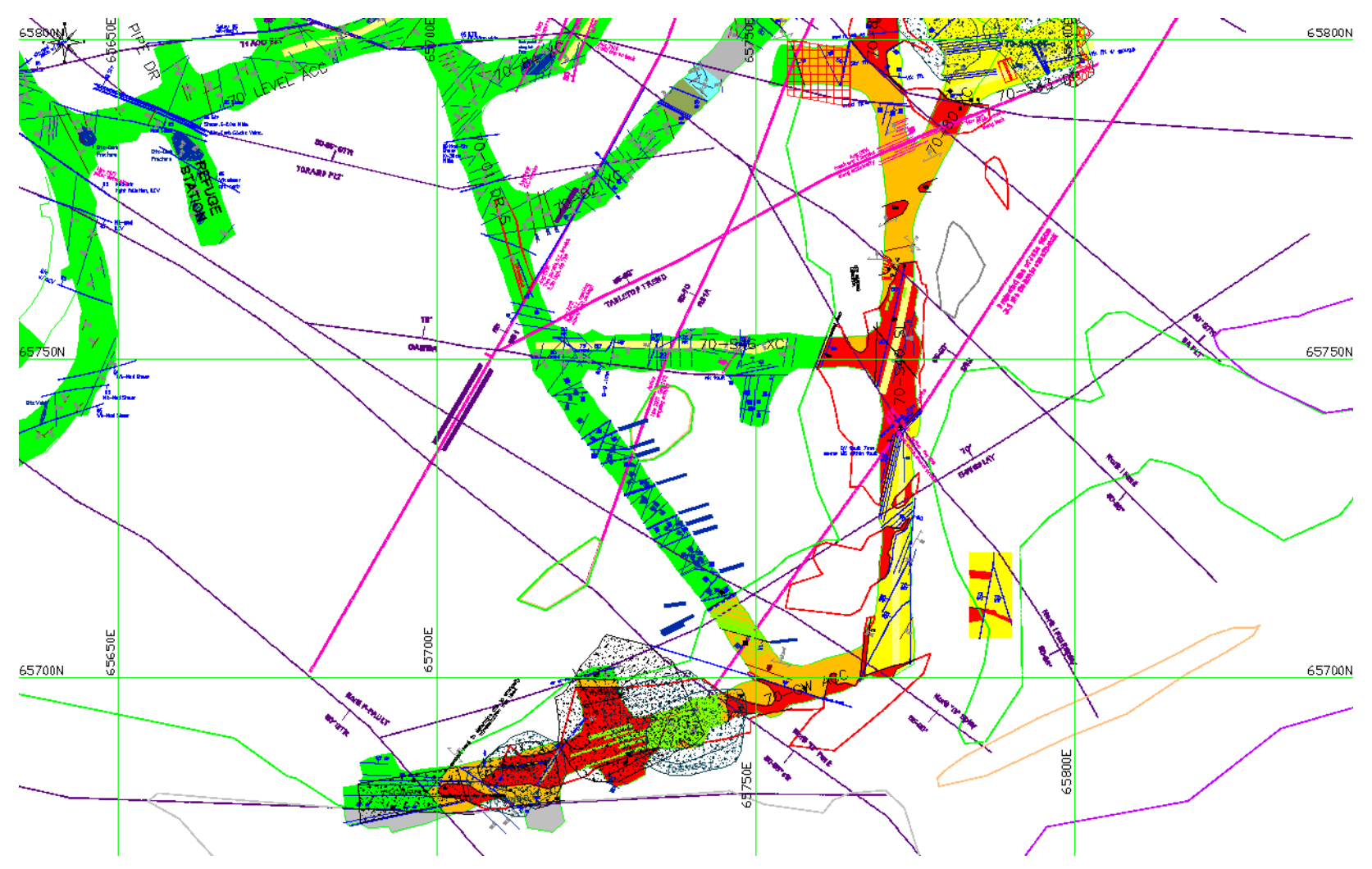

Figure 6 Partial geology plan, 7,000 level, centred on the location of the $M_{N} 1.96$ seismic event of 18 December 2018. The event occurred along Seismic Break 1A, roughly in the core of the pillar between the previously mined Greywacke stopes and the recently blasted 71-S43 Stope, which is located at the top of the figure, just to the right of centre (red square hatch)

Damage from the event of 18 December 2018 associated with the final blast in the 71-S43 Stope is shown in Figures 7 through 13, where ground support tendons, the mesh, or both failed as a result of the event and associated regional displacement on the SB1A slip surface. Tendons were observed to have failed in shear, combined with significant bulking and distension of the rock mass. The observed failures allowed the data obtained by the laser scanner to be 'calibrated' such that wherever deformation in excess of $7 \mathrm{~cm}$ was observed, there was a high probability that the support capacity was reduced, and wherever deformation in excess of $13 \mathrm{~cm}$ was observed, the tendons could be assumed to have locally failed and to have no residual capacity. This is a conservative assumption given that ongoing production is likely to continue to trigger regional 'fault slip' seismic events on the same shear surfaces over the remaining mine life. Assuming that all tendons have failed or are loaded to near capacity and require complete replacement will provide the highest level of assurance that the maximum support capacity will be available during subsequent seismic events, thereby lowering risk both to personnel and to the mining process. The relationship between the observed deformation, the mobilised fault systems and the Abaqus stress model output associated with the mining of the 71-S43 Stope is shown in Figure 14. From the model, it was anticipated that the deformation would be concentrated along members of the seismic break rupture surfaces, most notably SB1A. For the most part, the damage observed was consistent with the areas of high strain predicted by the model. 


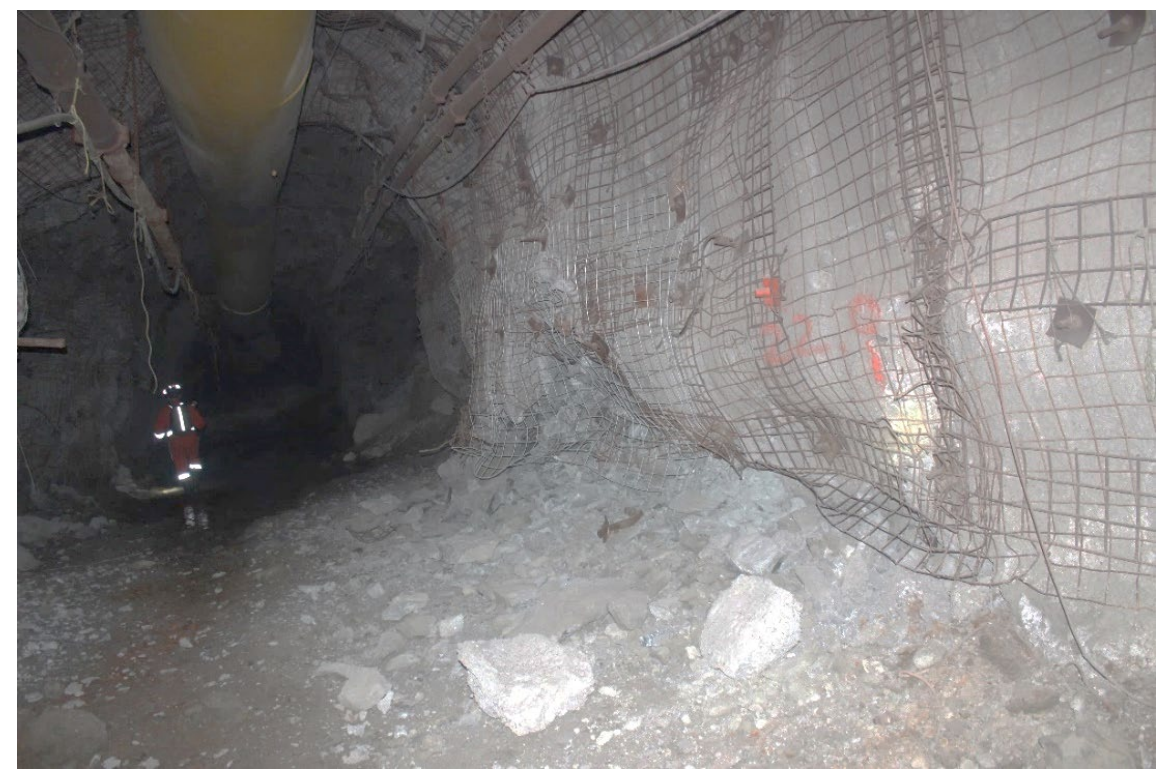

Figure 7 Ejected material, 70-S46 XC south wall and floor, near the trace of the Seismic Break 1A (SB1A) rupture surface, 19 December 2018. Note the number of cupped plates on the bolts in the walls, indicating load in excess of 17 tonnes on the tendons. Also, note the failed Super Swellex bolt, which has been both sheared and bent, potentially originating from the north wall, at the SB1A rupture surface in the centre of the image

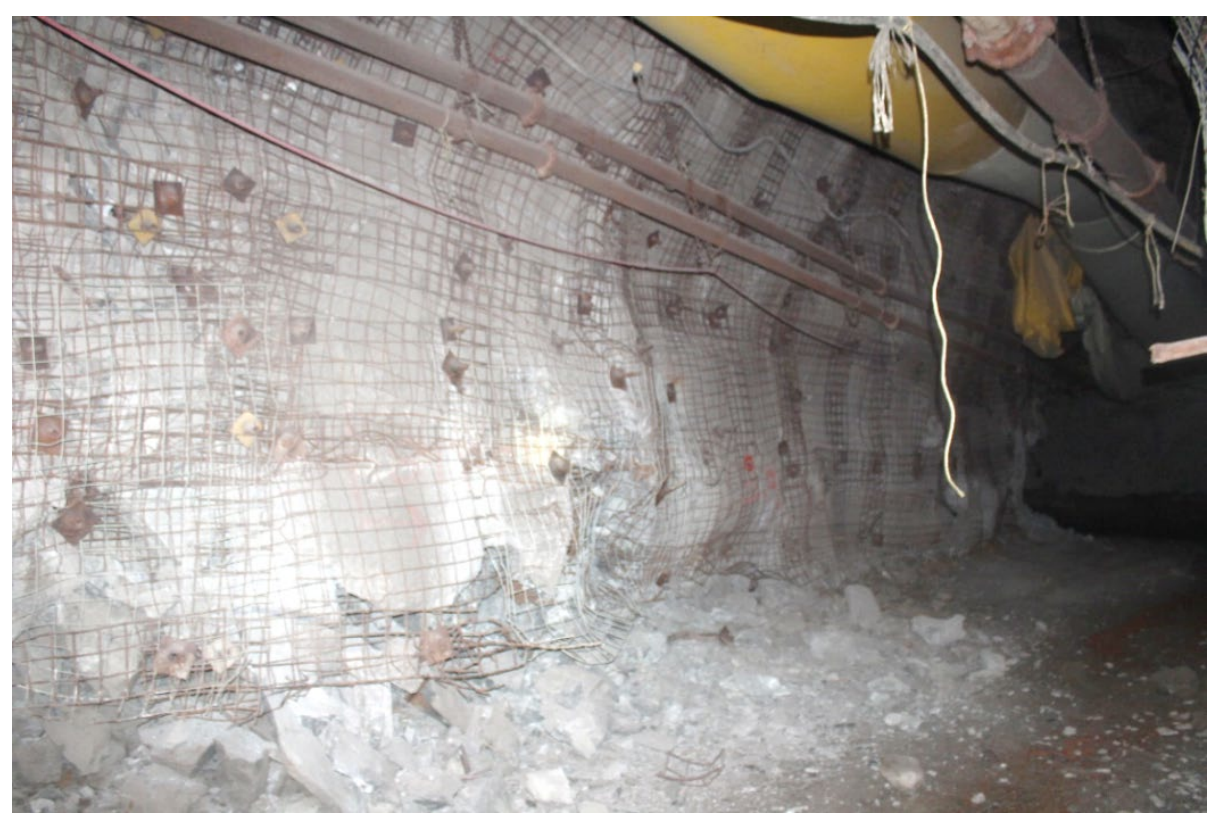

Figure 8 South wall of 70-S46 XC, facing west. Note the shattered nature of the rock mass and the amount of damage to the ground support systems, including bent plates, missing bolt heads and damage to the burst-rated membrane support near the drift floor, where the support has the highest loading (since the floor is not bolted) 


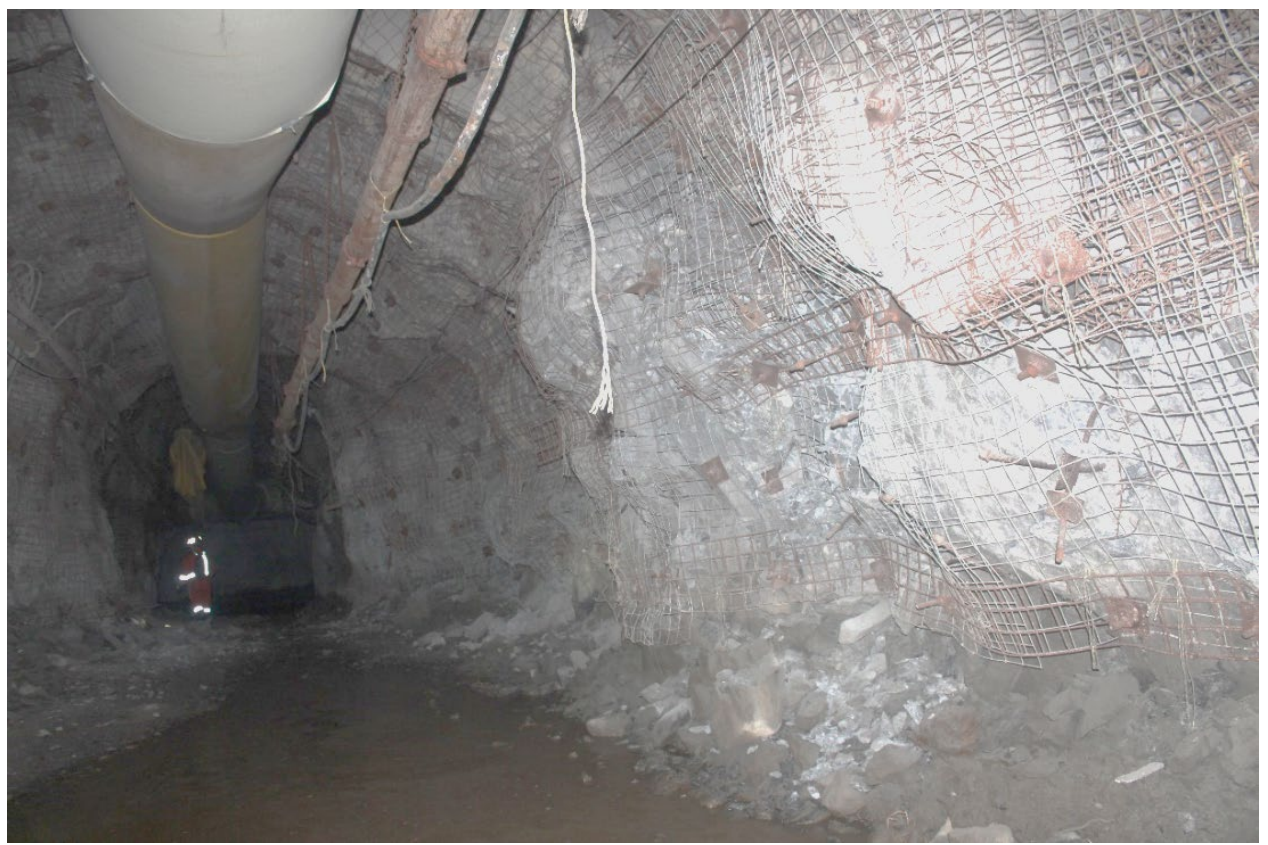

Figure 9 North wall of 70-S46 XC, facing west. Note the highly shattered rock mass in the upper wall near the centre of the image, contained by the mesh. Note historic rehabilitation resulting in heavy ground support covering older 'bent over' bolts, done following the $2011 \mathrm{M}_{N} 3.8$ burst, confirming that re-support is necessary following high-magnitude events since the development remained intact even though the slip surface crossed directly through it

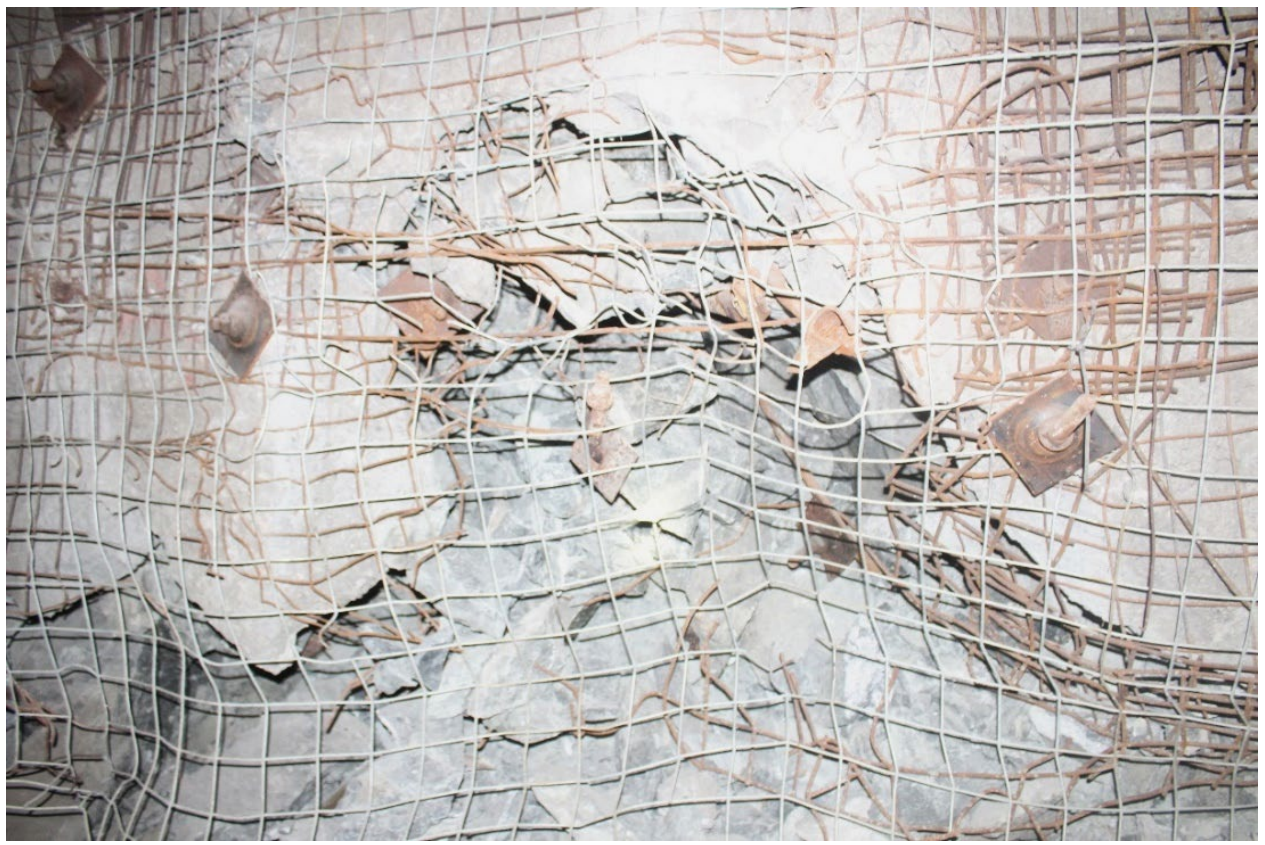

Figure 10 Close-up of damage shown in Figures 7 and 8 on south wall of $70-S 46$ XC. At least two bolt plates have been pulled through the mesh, with at least one new bolt having been pulled through an older 0 -gauge strap that had been covered by mesh during a previous rehabilitation campaign (just left of centre of image) 


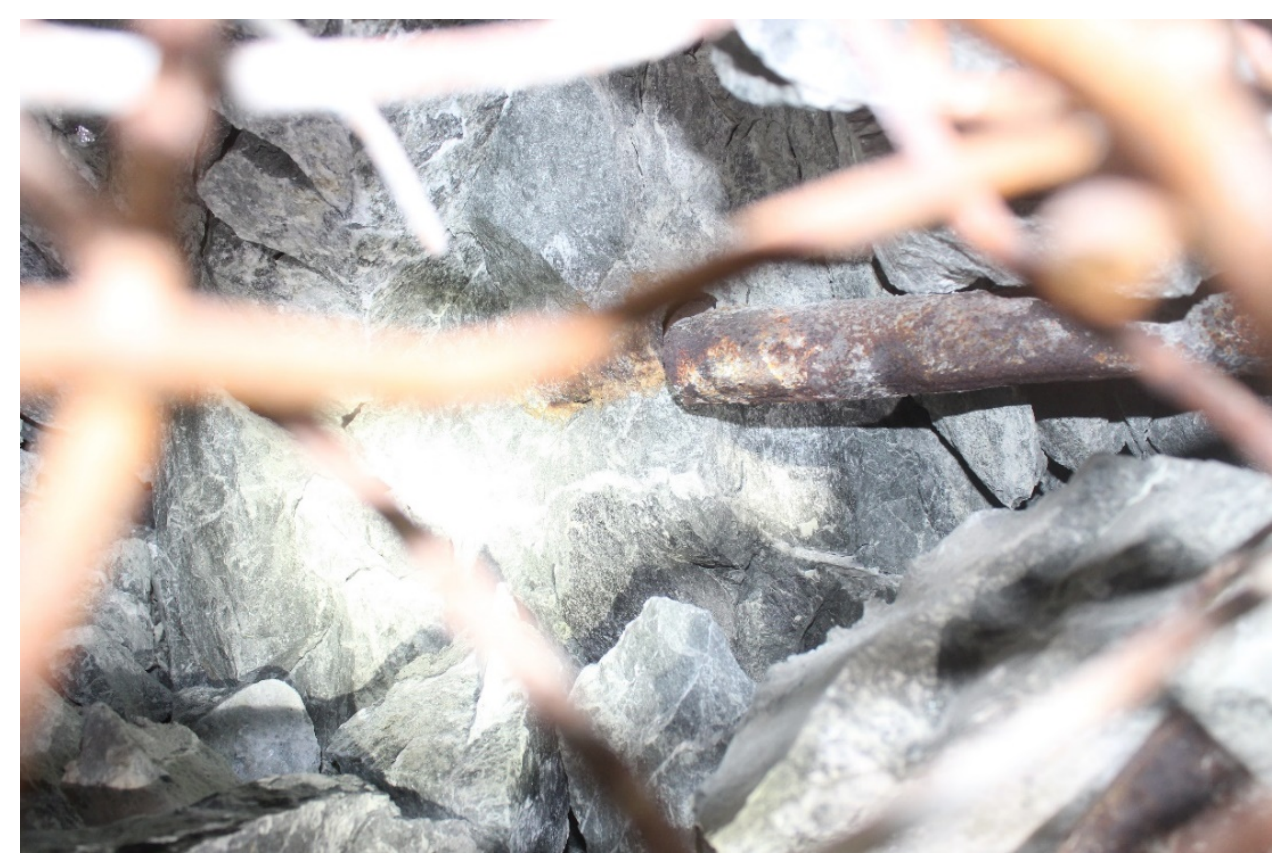

Figure 11 Close-up of sheared D bolt in the same area as Figure 10. This bolt had to be loaded to in excess of 25 tonnes to fail. Failure through full diameter shank of bolt, below highest deformed anchors near collar of bolt

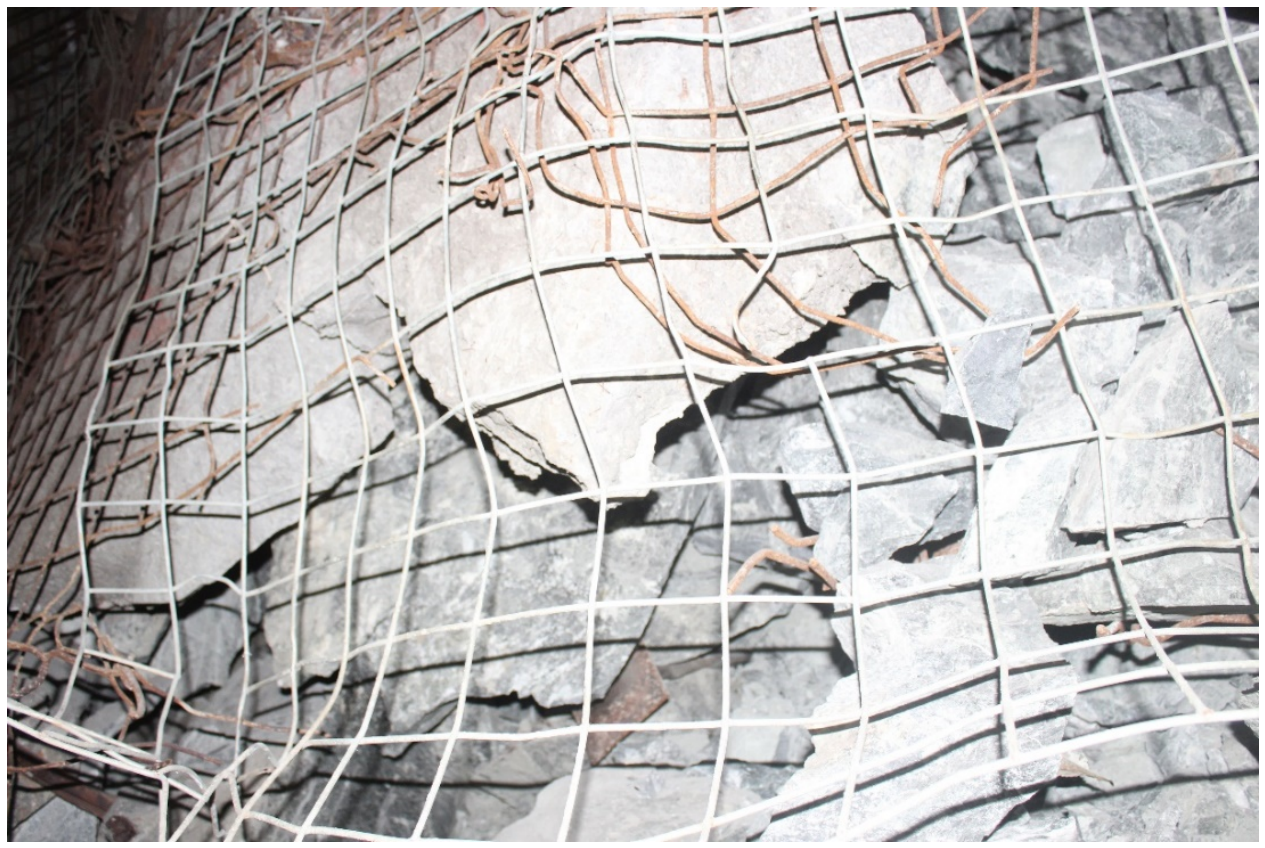

Figure 12 Close-up of lower east side of damage area from Figure 10. Note in the lower centre of the image the $D$ bolt, which has remained in its original location. The rock mass has bulked out well beyond the plate of the bolt and has torn the mesh at the original point of attachment (lower left corner in figure). There has been over $40 \mathrm{~cm}$ of displacement in this area since it was originally scanned in August 2017 and in excess of $20 \mathrm{~cm}$ of displacement as a result of the production blast and associated seismic event since the drift was scanned on 7 December 2018, as shown by the most recent scan taken 19 December 2018 


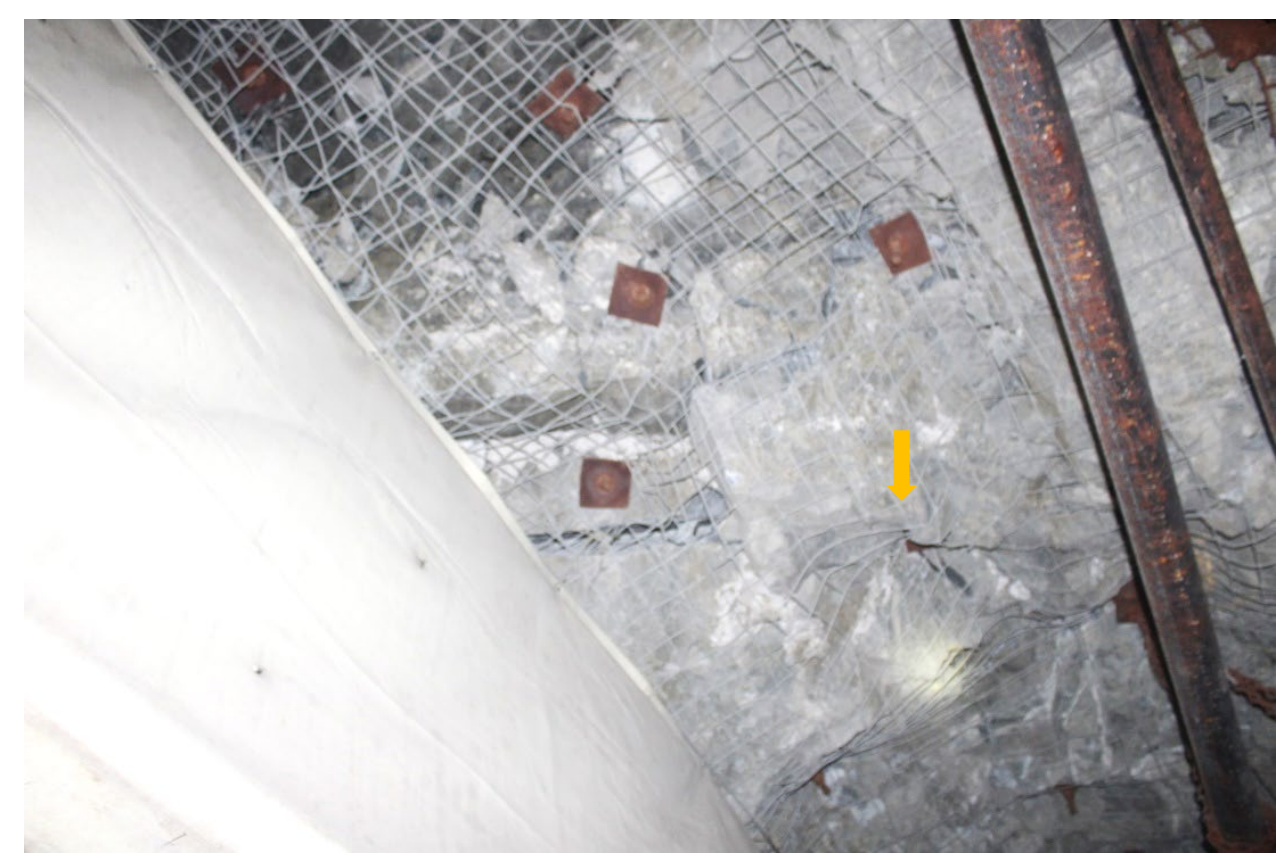

Figure 13 Back of 70-GW Acc just south of Seismic Break 1A (SB1A) intersection, facing north. Note the open shallow joints in the roof, where wedges have formed to the hanging-wall side of SB1A. Also, the plates have become dog-eared, indicating either increased load on the support system or the rock mass bulking to the point where individual bolts are almost no longer visible (at arrow)
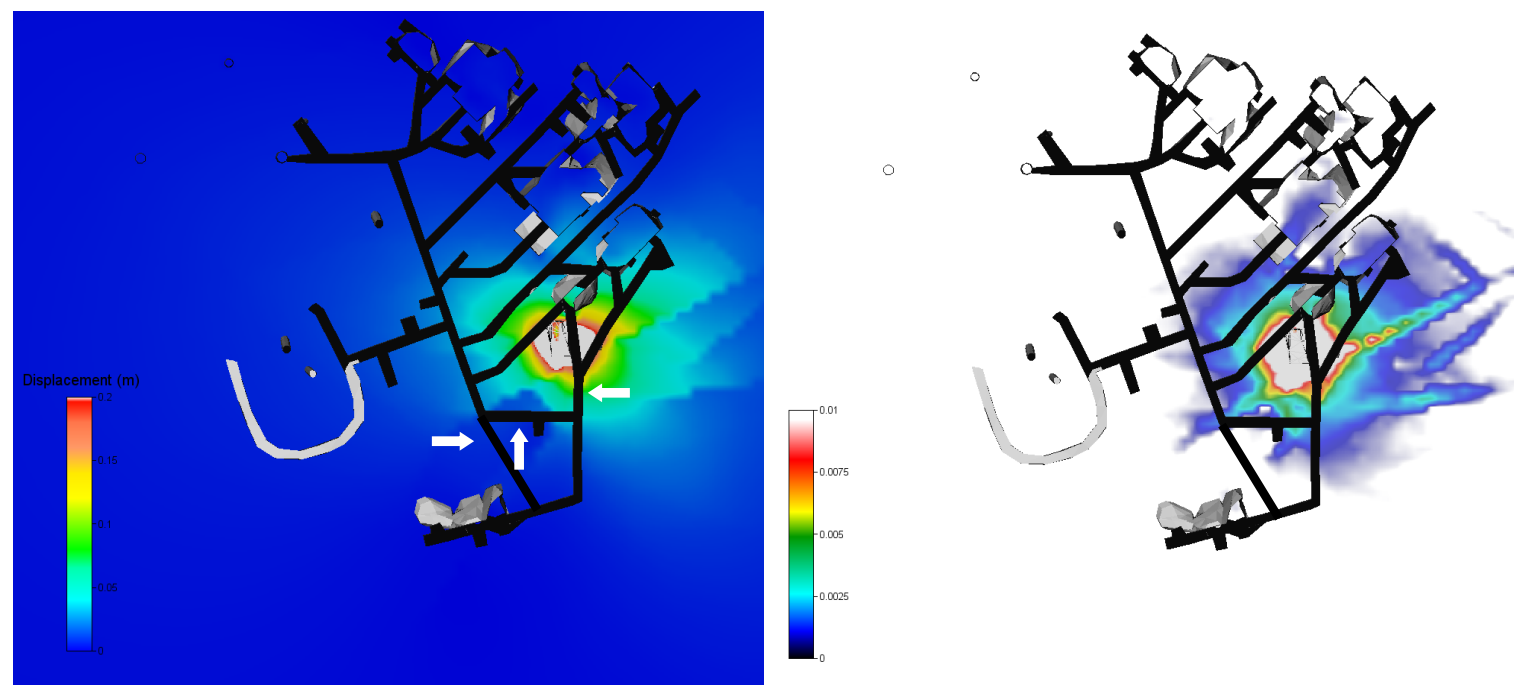

Figure 14 Deformation and strain plots for the 71-S43 Stope, from the 19th version (sequence update) of the Abaqus stress model (Beck Engineering Pty Ltd 2018). Note the strong 'boundary' in the magnitude of deformation created by the Table Top Trend and other structures, including Seismic Break 1A indicating a high potential for 'fault slip' seismicity. Note how the strain is focused along unique structures in the accompanying strain plot for the same stope. Plot centred on the stope volume, $20 \mathrm{~m}$ below the 7,000 level. Structures intersect development on the overcut elevation at arrows in left image

In the first image in Figure 15, the deformation is shown from the most recent sets of scans; in the 70-01 S and 70-S46 XC, those scans were taken on 7 December 2018 and 19 December 2018 respectively; therefore, the deformation occurred within a 12-day period, almost all of it associated with the 71-543 Stope final blast and subsequent $M_{N} 1.96$ induced seismic event of 18 December 2018. The scans for the 70-GW Acc were done on 27 June 2018 and 19 December 2018 respectively, and they have been digitally 
stitched to the scans taken in the 70-01 and 70-S46 XC. As shown in Figure 16, almost all the deformation is concentrated along the SB1A rupture plane (compare yellow and red areas with mapping in Figure 6). The deformation areas identified in the ZEB scans correlate with the damaged rock mass and ground support as described in the observations above.
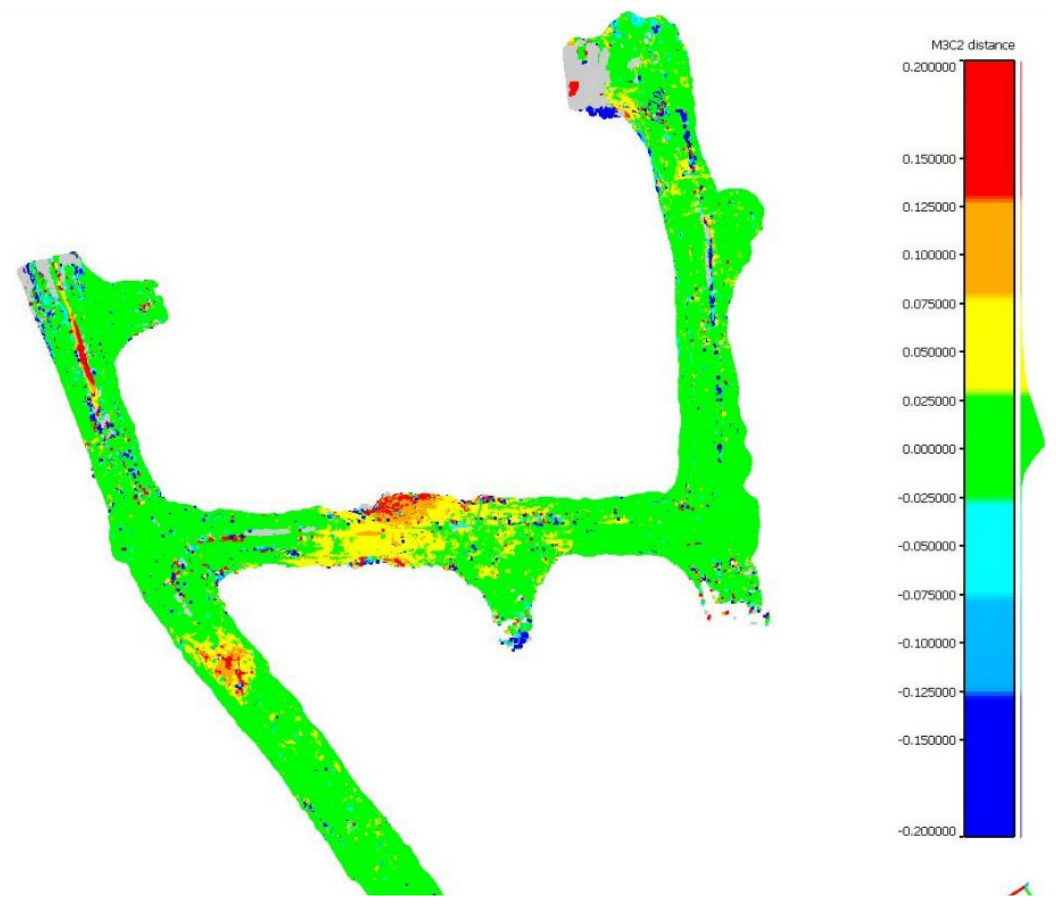

Figure 15 CloudCompare output file for merged ZEB scans of the 70-01 S and 70-S46 XC (taken on 7 December 2018 and 19 December 2018), and for the 70-GW Acc development (taken on 27 June 2018 and 19 December 2018 respectively). Very little change was observed in the 70-S40 SL (northeast corner of image) over this relatively short period, even though this access leads directly to the overcut of the 71-S43 Stope

Over a longer period, the deformation associated with mining other south abutment stopes, such as the 73-848, 70-S43, 69-883, 75-S05 and 69-789, becomes more apparent. See Figure 16, which separates the most recent deformation attributed to the $M_{N} 1.96$ seismic event and/or the final blast in the 71-S43 Stope (lower right of image) from the longer term creep within the area that occurred between 25 August 2017 and 7 December 2018 (upper left part of image). It is apparent not only that long-term deformation (creep) is clearly associated with the SB1A rupture surface but also that the most significant rock mass damage from the 71-S43 Stope final blast and subsequent seismic events is also concentrated in an area that had the most long-term deformation and therefore the highest 'pre-burst' strain induced into the ground support systems (i.e. bolts and mesh in the area had been loaded by static strain and were therefore more prone to failure under the subsequent induced dynamic load).

When the earliest and most recent scans are compared (after merging the 7,000 GW Acc development scans), the total deformation from 25 August 2017 to 19 December 2018 is much more significant. Since the period is longer, the area where deformation exceeds $13 \mathrm{~cm}$ has grown disproportionately and includes the combined effects of long-term creep, with recent seismicity tied to fault slip. Given that some of the displacement is very gradual, it makes identification of at risk areas extremely difficult if solely using visual clues; the scanner is capable of resolving changes in the profile of the development greater than $+/-2.5 \mathrm{~cm}$, which would be difficult to identify visually, and below which would be unlikely to cause significant damage to support systems. 


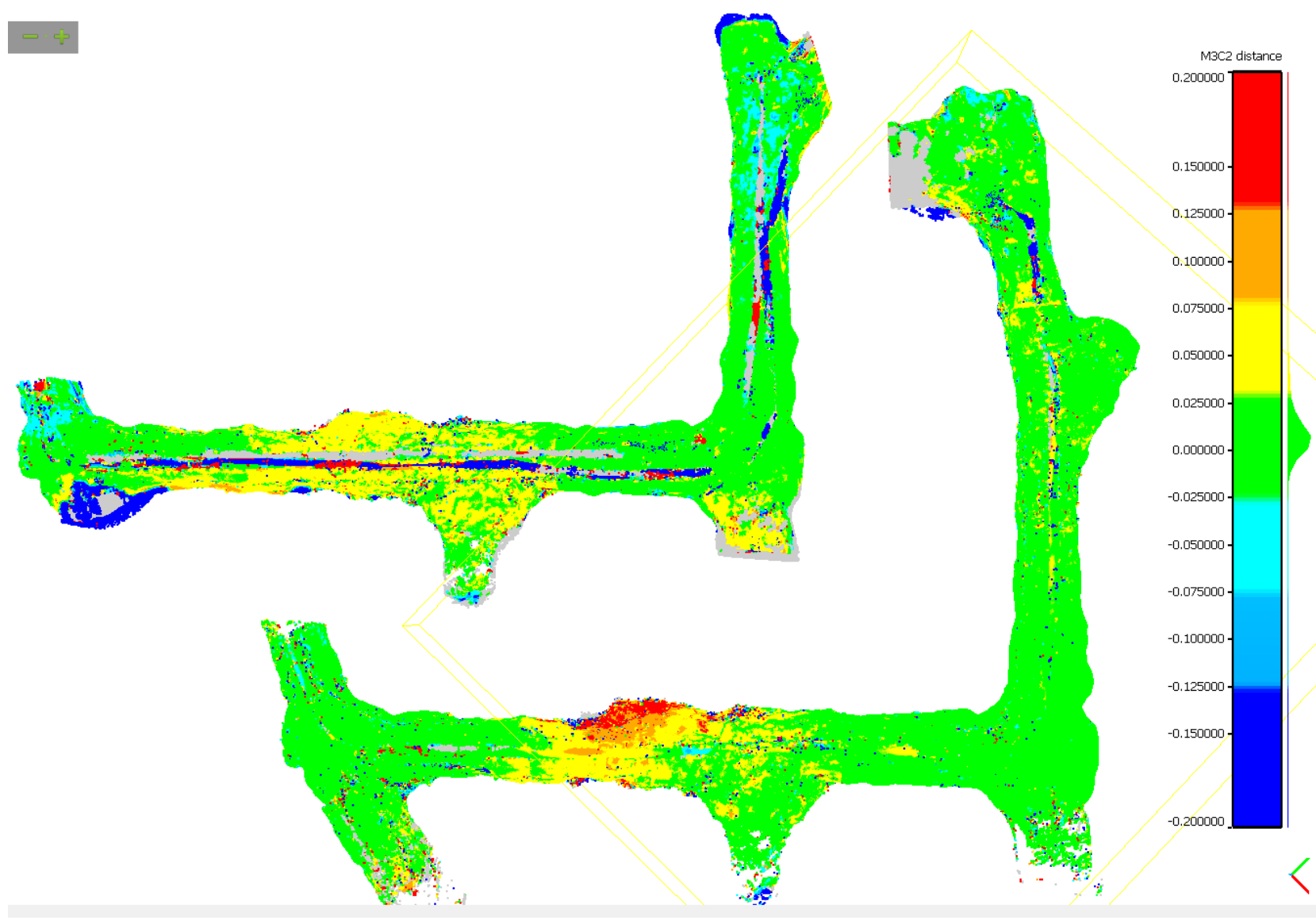

Figure 16 Deformation plots for 70-S46 XC and 70-S40 SL for two periods. Upper left image is scan comparison from 25 August 2017 to 7 December 2018, showing deformation trends over a 15.5 month period, associated with mining a number of stopes in the south abutment of Block 1, and possible effects of mining south abutment stopes in Block 2 and Phase 2. Lower right image is scan comparison from 7 December 2018 to 19 December 2018, which only includes the deformation and seismic activity associated with the final blast in the 71-S43 Stope. The most significant damage is concentrated along the Seismic Break $1 \mathrm{~A}$ lineation. The 70-GW Acc development did not exist in 2017 when the first scan was taken; therefore, there is no 'area' to compare in the longer period scan (dark blue)

An area associated with the eastern extension of either the Table Top Trend or some other seismically active structure is also apparent in the 70-S40 SL, just north of the 70-S46 XC. There is also evidence of ongoing deformation of up to $7 \mathrm{~cm}$ in the back of the 70-GW Acc/70-GW DD intersection (extreme southern end of the image), which closely aligns with the Seismic Break 2 (SB2) rupture plane. This makes sense, as the SB2 would be mobilised by the mining of the Stopes 75-S26B, 70-S43 and 69-789 and others higher in the Phase 2 south abutment (see Figure 17). Scanning data may also allow failure planes to be more accurately located, particularly where bulking of the rock mass could mask the actual slip surface.

\section{Conclusion}

There appears to be a sound basis for the use of SLAM laser scan technology to define areas where ground support systems require replacement or rehabilitation. At present, areas showing in excess of $7 \mathrm{~cm}$ of deformation are considered at increased risk of failure during subsequent mining-induced seismicity, and they are either closed for immediate re-entry after longhole blasts as part of the normal seismic re-entry protocol or are scheduled for rehabilitation prior to the blast if high levels of seismicity are anticipated and the area is required for long-term/life-of-mine access. Areas showing in excess of $13 \mathrm{~cm}$ of displacement are deemed to require re-support if in permanent mine infrastructure or if continued man entry is required. 
Further research to link the magnitude of surface rock mass displacement to the underlying condition of the tendons is warranted. This could include the overcoring of ground support tendons to measure actual bolt strain and to check for evidence of bolt failure, including breaks caused by excessive axial loading or due to shear, or by the placement of instrumented bolts in areas deemed at risk of high loading, which could then be compared with future scan data.
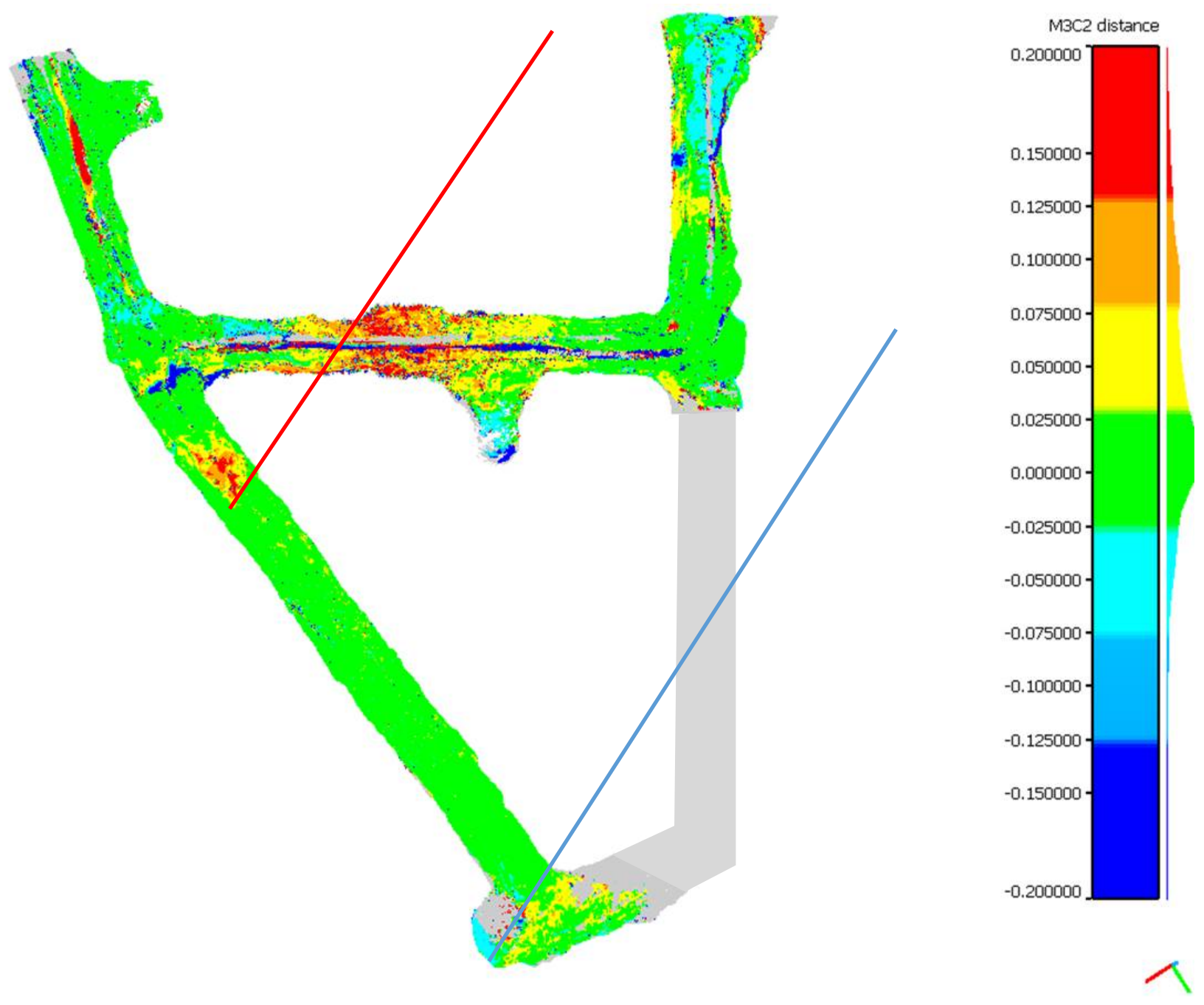

Figure 17 CloudCompare deformation plot, south end of 7,000 level, from merged scans taken 25 August 2017 and 27 June 2018 (70-S46 XC and 70-GW Acc respectively), which were considered 'baseline', compared with the scan of 19 December 2018. This scan comparison shows total deformation over a 16-month period and indicates the areas at highest risk of future damage due to induced bolt loading or failure. Seismic Break 1A (red) and Seismic Break 2 (blue) rupture trends have been superimposed on the scan image for reference. The scan data may allow further refinement of the actual break surfaces (sliding planes), as the exact location of the surface can occasionally be difficult to identify in extended zones of intense fracturing and rock mass bulking

\section{Acknowledgement}

The author would like to thank Gregory Cooper for executing and processing the scan data and for undertaking the mapping of ongoing structural deformation within the mine workings. The author would also like to acknowledge Glencore Canada Corporation, Kidd Operations, for permission to publish this paper. 


\section{References}

Beck Engineering Pty Ltd 2018, Abaqus Stress Model Sequence 19 Voxler Files, Technical Report and data provided to Glencore Canada Corporation, Kidd Mining Division.

Counter, DB 2014, 'Kidd mine-dealing with the issues of deep and high stress mining-past, present and future', in M Hudyma \& Y Potvin (eds), Proceedings of the Seventh International Conference on Deep and High Stress Mining, Australian Centre for Geomechanics, Perth, pp. 3-22.

Hyett, AJ, Charette, FC, Forbes, BJ \& Engbretson, AC 2014, 'Enlightening bolts', in M Hudyma \& Y Potvin (eds), Proceedings of the Seventh International Conference on Deep and High Stress Mining, Australian Centre for Geomechanics, Perth, pp. 315-328.

Hyett, AJ, Forbes, BP \& Spearing, AJS 2013, 'Enlightening bolts: Using distributed optical sensing to measure the strain profile along fully grouted rock bolts', in T Barczak, D Caudill, G Lohr, SS Peng, S Tadolini, M Thompson \& B Warnick (eds), Proceedings of the 32nd International Conference on Ground Control in Mining, West Virginia University, Morgantown, pp. 107-112

Lopez-Pacheco, A 2018, 'Smart support-National Research Council brings ground support into the digital age with new rock bolt sensors', CIM Magazine, vol. 13, no. 2, pp. 34-35.

Simser, BP 2007, 'The weakest link: Ground support observations at some Canadian Shield hard rock mines', in Y Potvin (ed.), Proceedings of the Fourth International Seminar on Deep and High Stress Mining, Australian Centre for Geomechanics, Perth, pp. 335-348. 